\title{
Modern factors of health and their peculiarities for teenagers
}

\begin{abstract}
The work aimed at specifying modern features of civilizational factors influence on the health, revealing peculiarities of young age, establishing reflexion of modern factors of health in methodological approaches to health studying.

Changes in understanding health are reflected in its studying methodology. The analysis of sociological research data shows, that the social stress became the main reason of medical-demographic situation deterioration in days of reforms. The mechanism of its influence was the loss of effective labor motivation, social envy, and deterioration of spiritual condition of a society. Material well-being decrease was not a determinative factor. The problem of inequalities in health gets the increasing urgency. It is connected with physical and social living environment; availability of qualitative medical aid; specific features of behavior of people. At a medical aid guarantee, and at teenage age, factors of social living environment, which influence behavior in health sphere by means of stigmatization are especially significant.
\end{abstract}

Keywords: health, risk factors, adolescents, developmental age.

DOI: $10.2478 /$ pjph-2014-0034

Dynamics in a priority of health factors has been observed recently. It was interesting to biomedical factors in 1960-1970s. The tendency to social, economic and natural-geographic factors prevailed in the late eighties. Research studies of 1990s are characterized by drawing attention to social-psychological and behavioral factors of $2000 \mathrm{~s}$ - to those of cultural origin. The purpose of the work was to specify modern features of civilizational factors influence on the health, to reveal peculiarities of young age, to establish reflection of modern factors of health in methodological approaches to health studying.

Dynamics of approaches to definition of health. The functional approach

The history of medical science development totals some hundreds definitions of health. They are based, as a rule, on factors, which are the most important in health formation [1]. The analysis of studied factors has allowed. Zhuravlyova to draw a conclusion that their division into groups has no unification and inclusion of this or that factor in any of groups in various classifications rather subjectively and depends on a position of the researcher [2].

The collective of the Novgorod Centre of Russian Academy of Medical Science has proved the health concept, based on biological (the level of indemnification of somatic pathology; the level of nonspecific resistance of an organism; the level of functional adaptation; the level of the reached physical development) and social components [3]. Integrated indicators of biological component of population health were calculated on the basis of statistical data about age structure of morbidity and death rates [4]. Social indicators include the valuable attitude of individuals to health; knowledge of the population about diseases; a self-estimation of health; behavioral strategy of the population in health sphere; estimation by the population of availability of medical aid. Being based on the given approach, health is considered as a condition providing realization by individual of biological and social functions in full volume [3].

The same principle of estimations of completeness for realization of functions in health definition underlies the functional approach developed concerning health in the sociology. Its founder was T. Parsons. For him, health was optimum possibilities of the individual to carry out effectively the roles and problems for which he or she has been socialized [5].

However such approach absolutely justified from the logical point of view, is not coordinated with WHO health definition (a condition of full physical, spiritual and social well-being, and not just absence of illnesses and physical defects). According to it, the absence of illnesses and physical defects is an obligatory condition of health, and the presence of illnesses and defects a priori carries him or her to the category of patients. In spite of the fact that health in the modern conditions is the possibility of realization of biological and, first of all, social functions. Possibly, revision of the standard definition is justified all the same: the concept "health" becomes a synonym of "self-realization", and the statement that "the state of health is caused not only human biology,

${ }^{1}$ Chair and Department of Public Health and Health Protection Management, Grodno State Medical University, Belarus

${ }^{2}$ Chair and Department of Epidemiology, Medical University of Lublin, Poland 
but its spiritual potential, development of its subject world" [2] underlines the increasing quantity of researchers. I. V. Zhuravlyova while analyzing various approaches to health definition has come to conclusion that health is a social phenomenon, the product of social development connected with a certain historical period of time both its social and cultural conditions [2]. Generally, it is obvious, that the person with faultless physiological parameters cannot carry out any expedient, socially useful activity, and, on the contrary, the person burdened by some physiological lacks, can be useful for a society. Thus, social health in many respects depends on a social resources or the social capital of the person [6]. A. M. Osipov considers social conditionality of public health as a complex of the factors influencing a condition and dynamics of public health, covering quantitative and qualitative characteristics, the social organizations at the level of a society, local communities and a social microhabitat [7].

Changes in modern approaches to understanding health are reflected in methodology of its studying. The sociological method, which is carried out in the form of sociological monitoring becomes the integral and basic method of studying of health at the present stage [8]. O. P. Shchepin, V. A. Medik, V. I. Starodubov suggest to include the following modules in the sociological monitoring: the medical-demographic module; the module of population's self-estimation of the core aspects of state of health; the module of an estimation of activity of local system of public health services; the module including factors and conditions, influencing the population health [9].

\section{Civilization factors of health. The theory of social stress}

The Russian sociologists' analysis of major factors and the conditions provoking distribution of socially caused illnesses lasting 15 years has allowed to draw conclusions that such factors are important: changes of life-value orientations of people with prevalence of their hedonistic versions, change of representations about an ideal, rehabilitation of deviant forms of behavior, uncontrolled development of show business and morally defective advertising [10].

While analyzing the influence of social stress on the health of Russians, B. T. Velichkovsky has noticed not only reduction of the population of Russia, but also worse health condition, so that it loses the ability to serve as the power of economic revival [11]. According to Velichkovsky's thesis, the specific reason consisted in population's loss of effective labor motivation - possibilities of fair work to provide worthy existence to itself and the family [11]. Pathogenic mechanisms consist in an exhaustion of a general adaptable syndrome; failure of a dynamic stereotype of higher nervous activity. That, according to I. P. Pavlov, leads to occurrence of suicide moods, formation of the phenomenon of "the programmed death of an organism" orphenoptosis [12].

Agreeing with Velichkovsky's point of view, we will also add that effective labor motivation is the major component of spirituality of a society. By influencing a spiritual condition of a society, the labor motivation regulates also its health.

\section{Spirituality of a society as the pledge of its health}

The principle of spiritual-demographic determination proved in 2001 by I. A. Gundarov testifies to connection of a spiritual condition of a society and its health: with other things being equal, improvement (deterioration) of a spiritual condition of a society is accompanied by decrease (growth) of morbidity [13]. The hypothesis about involving in negative medical-demographic processes of moral parameters is thus proved.

It is remarkable that a famous sociologist P. Sorokin stated similar views on health. He analyzed the influence on health of such qualities and conditions of the person, as kindness and love: from among two subjects with identical biological organisms, the kind and affable person tends to live longer and with better health than the bad, and, especially, afflicted one with hatred [14]. Data of many research studies testify to connection of health with harmony and spirituality. L. G. Matros considers health as the process of harmonious interaction of social and biological factors in the person, providing to it stability in mutual relations with an environment [15]. V. N. Rostovtsev considers that there exist two approaches to health estimations: from positions of norm and from harmony positions. Harmony standards are always absolute and always are fundamental [16]. Within the same norm, the individual harmony can essentially differ. As Rostovtsev writes norm definition is a more rough tool of estimations of health, and harmony definition represents more thin, the precision tool [17].

Spiritual condition of a society as the set of its socially significant ideas and systems, can serve both a risk factor, and the stability factor in development of crisis of labor motivation. The mechanism of the given influence is social envy: a phenomenon of subjective pauperization [18]. The poverty in itself is the ambiguous phenomenon. N. M. Davydova specifies that theoretical-methodological approaches to poverty start with three basic concepts: the absolute, based on formal conformity of incomes to the established minimum of means; subjective, based on estimations of own position by people; and relative, assuming, that the establishment uniform minimum "a poverty threshold" in different communities, at least, is problematic and depends on an average level of life of the specific country [19]. Subjective pauperization is illustrated visually by a problem of a mismatch of level and quality of life of the population of Belarus. This problem was addressed by G. N. Sokolova by results of national sociological research "The level and quality of life of the Belarusian population" (November-December, 2009). Sokolova has noted the presence of essential distinctions between a city and village, Minsk and regions. Quality of life has been estimated as high by $1.2 \%$ of respondents in regions and $0.0 \%$ in the Belarusian capital, and "below an average" by $19.1 \%$ of inhabitants of regions and $29.1 \%$ of inhabitants of Minsk [20]. Objective data of the same research show that the part of people in the range from the living wage budget to the minimum consumer budget has decreased from $42.0 \%$ to $16.3 \%$ in the period between 1995 and 2009. Thus, positive dynamics of security of the population, hence, of a standard of living of Byelorussians, is obvious [20].

At the same time, the results of national sociological research (2008-2009) of families with children, by S. N. Burova show that: concepts about an average level of security of family in Belarus and, for example, family in the Western and Northern Europe disperse. Even the simple list of the 
goods of long use available for respondents shows that they are difficult for achieving at the middle class level. Most likely, respondents compare themselves to the nearest social environment and, seeing, that they live also, as well as neighbors, colleagues, relatives, compare the families to an average level. Only every eighth of the interrogated men and women are completely satisfied by a financial position of the family [21].

By developing Gundarov's ideas, V. N. Rostovtsev has formulated organic principles of social determination of health: social spirituality defines dynamics of all kinds of biological and social load; social justice defines the size of emotional load and, accordingly, frequency of a psychodependent and psychosomatic pathology; social security influences health of old men and children, and also demographic dynamics [22].

The spiritual condition of a society forms also quality of life of its members, their social well-being. On a number of definitions, quality of life represents system of life values characterizing creative activity, structure of requirements and conditions of development of the person and a society, satisfaction of people with own life, social relations and environment $[23,24]$. V. I. Evdokimov. writes: finding the true quality of life is answered only with the success that can be reached without a damage to spiritual qualities of the person and spiritual development of a society as a whole [25]. The author specifies that in a number of research studies in which statistical materials from 23 countries of Europe and America have been included, it is established that financial condition has ambiguous influence on viability of the person and population health. For example, at transition of the countries from a category of "poor" to a category "average" at the level of a share of gross national product per capita, morbidity and death rates decrease is marked. Any further improvement of well-being of a society (transition to a group of the rich countries) is accompanied by a phenomenon of deterioration of health of its members, growth of death rate due to some diseases. It has been noticed, that a principle "The higher standard of living, the better health" exists in certain limits and is true not for all components of quality of life and diseases. In some cases, if there is a spiritual trouble, it is not true. Then the Gundarov's principle of spiritual-demographic determination comes into force.

\section{"Inequality in health", its peculiarities at the age of teenagers}

The problem of inequalities in health gets the increasing urgency among various groups of the population, including economically developed countries [26]. Economic inequality as the factor limiting possibilities of maintenance of health has been known for a long time. The urgency of the given factor remains and now the lower social and economic status people have, to a lesser degree they can supervise the life and a state of health [27].

Factors of employment, subjective poverty, social spirituality, social justice and social security are the regulators influencing the health of each individual person and a society as a whole. Possibly, basic mechanism of their influence has the psycho-somatic nature. The lifestyle acts as the basic tool of social factors influence on health. Lastly, in turn, it depends on a social environment, including a degree of a social inequality [28]. Thus, the social inequality itself cannot serve as a poverty synonym.

As I. V. Zhuravlyova marks, usually the inequality in health sphere is connected with three groups of factors: economic resources, the physical and social environment in which people live; health services with different possibilities for different categories of the population - that is inequalities in availability and possibility of quality medical service; specific features of behavior of people [26]. Thus, the inequality in health is considered now not so much as economic, as territorial, educational, socially-demographic, information inequalities which influence objective conditions of formation of health of the population, first of all of young generation [29]. To the listed aspects of an inequality in health, certainly, it is necessary to add one more. It is a spiritual inequality.

At young age, especially at the teenagers living in Belarus, superiority among the factors promoting an inequality in health belongs to a physical and social living environment. Influence of the social environment on teenagers is accurately traced on a smoking example. So, in one of research studies it has been revealed that smoking of the Russian teenagers is closely connected with the place of living [30]. It has appeared at more detailed study, that high rate of smoking at boys from villages and at girls from a megacity is caused by different factors of social character. Therefore, at girls from large cities it was the factor of smoking mother. At boys from villages it was the low self-estimation caused by the affiliation to stigmatized, according to boys opinion, group (inhabitants of small settlement) [30,31]. The example of consumption of alcohol by teenagers also confirms the influence on health of teenagers and their behavior in this sphere of the inequality of a physical and social living environment. It is established that the teenagers-boys living in rented apartments or hostels, more likely consume alcohol [32]. The influence of the type of habitation, a specific social environment in which risky health behavior is a norm, the public opinion is tolerant, and alcohol is accessible. The unequal living environment influences health and behavior in health sphere by means of stigmatization, or affiliation in the general social structure. Stigmatization leaves traces on the process of the person's identification in the community and in a society [33]. It makes the person successful or unsuccessful only because he or she belongs to a certain group: place of living, education, behavior manner.

\section{CONCLUSIONS}

The concept of health including biological and social components is most popular now. Health is considered as a condition providing realization of functions inherent in an individual, in full range. The principle of an estimation of completeness of functions realization underlies the functional approach to the health developed in sociology. Though such approach is justified logically, it is not coordinated with WHO definition of health. According to it, absence of illnesses and physical defects is an obligatory condition of reference of an individual to the healthy ones, and their presence means that a person is sick. It is thus obvious that health is a possibility of social functions realization 
first of all, which is caused not so much by biology, as by spiritual potential, and depends on social capital of the person.

Changes in understanding health are reflected in methodology of its studying. The sociological method becomes the core. The analysis of sociological research data shows that the social stress became the main reason of medicaldemographic situation in Russia deterioration in days of reforms. The mechanism of its influence was the loss of effective labor motivation, social envy and deterioration of spiritual condition of a society. Material well-being decrease was not a determinative factor. The problem of inequalities in health gets the increasing urgency. It is connected with physical and social living environment; availability of qualitative medical aid; specific features of behavior of people. At a medical aid guarantee, and also at teenage age, factors of social living environment which influence behavior in health sphere by means of stigmatization are especially significant.

\section{REFERENCES}

1. Frolova YG. Sociocultural health standard as one of characteristics of Belarusian mentality. Ethnosocial and confessional processes in a modern society. Grodno: GrSU; 2006.

2. Zhuravlyova IV. The attitude to health of individual and society. Moskow: Science; 2006.

3. Medik VA. Some methodical approaches in studying of health of the population. Problems of social hygiene, health services and history of medicine. 2009;6:8-11.

4. Medik VA, Tocmachev MS. Modelling of integrated indicators of estimation of population health. Health services of the Russian Federation. 2003;6:17-20.

5. Parsons T. The System of modern societies. Moskow: Aspect; 1998.

6. Jadov VA. Social resource of individuals and groups as their capital: possibility of application of universal methodology of research of real stratification in the Russian society. Who and where aspires to conduct Russia? Actors of makro-meso- and microlevels of modern transformational process. Moskow: MVSHSEN; 2001.

7. Osipov AM. The social statistics of public health: methodological problems. In: V.A. Medik (ed). The collection of works of Novgorod Centre of Science of Northwest branch of Russian Academy of Medical Science. Moskow; Publishing House Russian Academy of Medical Science; 2006.

8. Schepin OP, Ovcharov VK. To development of methodology in researches of public health. Bull Russ Acad Med Scie. 2004;4:38-43.

9. Schepin OP, Medik VA, Starodubov VI. Studying of population health at the present stage of development of a society. Problems of social hygiene, health services and history of medicine. 2005;5:3-6.
10. Grtigoriev SI. Counteraction to socially caused illnesses. Sociol. 2006;2:160-167.

11. Velitchkovski BT. Social stress, labor motivation and health. Public health services of the Russ Federat. 2006;4:8-17.

12. Pavlov IP. Full collected works. Moskow: Publishing House of Academy of Science; 1951.

13. Gundarov IA. Demographic accident in Russia: the reasons, the mechanism, overcoming ways. Moskow: Editorial URSS; 2001.

14. Sorokin P. The main tendencies of our time. Moskow: Science; 1997.

15. Matros LG. Social aspects of health problem. Novosibirsk: Nauka; 1992.

16. Rostovtcev VN, Rostovtceva VM. Bases of culture of health: Manual for teachers and tutors of educational establishments. Minsk: National institute of education; 2008.

17. Rostovtcev VN. Bases of health. Minsk: Minsktipproekt; 2002.

18. Bobkov VN. Poverty, level and quality of life: methodology of the analysis and realisation mechanisms. A standard of living of population of regions of Russia. 2005; 1:7-20.

19. Davydova NM. Deprivational approach in poverty estimations. Sociol. 2003;6:88-96.

20. Sokolova GN, Sechko NN, Taranova EV. Level and quality of life as transition preconditions to a postindustrial society. Sociol. 2010;4:4252.

21. Burova SN. Conditions of life of a family as the factor of well-being. Sociol. 2010;2:85-99.

22. Rostovtcev VN, Marchenkova IB, Kuzmenko VE, et al. The law of spiritually-demographic determination. Me news. 2009;6:42-44.

23. Evdokimov WI, Esaulenko IE, Gubina OI. Quality of life: an estimation and the system analysis. Voronezh: Sources; 2007.

24. Ushakov IB. Quality of life and health of human. Voronezh: Sources; 2005.

25. Evdokimov ИИ. Methodological aspects of an objective estimation of quality of life of Russian population. Medical and biologic and sociallypsychological problems of safety in extreme situations. 2008;1:23-32.

26. Zhuravlyova IV. Social problems of health of teenagers [Internet]. Children and Youth. Internet-Conference; Moskow, 2010 March 3 - Apr 4 [http://www.ecsocman.edu.ru/db/msg/334891.html]

27. Braun J, Panova LV, Rusinova NL. Social inequalities and health. Sociol. 2007;6:114-22.

28. Padiarova AB. Social Inequality in the factors model of Young Russians health. The Bulletin of Volga region of Academy of Public service. 2009;2(19):36-43.

29. Padiarova AB. Social Inequality as the factor of health of new generation of Russians. News of higher educational institutions. Volga region. Sociol. 2009;1:2-12.

30. Perlman F, Bobak M, Gilmore A. Trends in the prevalence of smoking in Russia during the transition to a market economy. Tob Control. 2007; 16:299-305

31. Ferguson (Anderson) GM, Cramer P. Self-esteem among Jamaican children: exploring the impact of skin color and rural/urban residence. J App Develop Psychopathol. 2007;28:345-59.

32. Kislitcina OA. Social-economical factors, determining the familiarising of the Russian teenagers with consumption of psychoactive substances [Internet]. Children and Youth. Internet-Conference; Moskow, 2010 March 3 - Apr 4 [http://www.ecsocman.edu.ru/db/msg/334891.html]

33. Elsukov AN. Stigmatization as a way of allocation of objects in structures of communicative action. Sociol. 2010;4:3-9.

\section{Corresponding author}

Halina Piecewicz-Szczęsna

Medical University of Lublin; Chair and Department of Epidemiology

1 Chodzki Str., 20-093 Lublin, Poland

tel./fax 081-742-37-71

E-mail: halpiec@wp.pl 